\title{
AC 2009-2037: INVESTIGATION OF THE SUCCESSFUL EFFORT TO CHANGE EDUCATIONAL CURRICULUM FRAMEWORKS IN MASSACHUSETTS TO INCLUDE ENGINEERING AND TECHNOLOGY
}

\section{Nataliia Perova, Tufts University}

Nataliia got her M.S. in Mathematics, Science, Technology and Engineering education from Tufts University in 2008 and M.S. in Electrical Engineering in 2005 from Tufts University and B.S. in Electrical Engineering from Suffolk University. Nataliia is currently a research assistant at Harvard Graduate School of Education where she is involved in the research project on mathematics education. She is also doing research on using engineering approaches to teach science to college students.

\section{Chris Rogers, Tufts University}

Chris got his PhD, M.S. and B.S. at Stanford University. He is a Professor of Mechanical Engineering at Tufts University and Director of the Center for Engineering Outreach. His research interests include: particle-laden flows, telerobotics and controls, slurry flows in chemical-mechanical planarization, the engineering of musical instruments, measuring flame shapes of couch fires, and in elementary school engineering education. He has a strong commitment to teaching and was awarded the Carnegie Professor of the Year in Massachusetts in 1998. He has worked with LEGO to develop ROBOLAB, a robotic approach to learning science and math.

\section{David Henry Feldman, Tufts University}

David Henry Feldman got his Ph.D. and M.A. from Stanford University in Child Development and Psychology; he also holds an Ed.M. from Harvard University and a BA from the University of Rochester. He is a Professor in the Eliot-Pearson Department of Child Development at tufts. His scholarly interests include: cognitive-developmental theory, the development of expertise, creativity, giftedness, prodigies, and religious conversion. He is a former Fulbright Scholar and was named Distinguished Scholar of the Year by the National Association of Gifted Children in 1988. He has made frequent media appearances on such shows as TODAY, NOVA, and Unsolved Mysteries. 


\title{
An Event So Rare: The Successful Effort to Change Educational Curriculum Frameworks in Massachusetts to Include Engineering and Technology
}

\begin{abstract}
In the increasingly technology-driven 21 st century, technological literacy became one of the important goals in our education. Understanding the fundamental principles of technology and an ability to think critically about technological development are essential qualities needed to make thoughtful decisions. In our research work we investigated the efforts in public schools to educate students about technology. In particular, we analyzed the process of development of the Technology and Engineering Curriculum Framework and its inclusion in Massachusetts's curriculum standards.
\end{abstract}

\section{Introduction}

In a world where technology plays a very important role, technological literacy becomes one of the important goals in our education. In 2002, the Technological Literacy Committee of the National Academy of Engineering issued a report stating that "technological literacy is essential for people living in a modern nation like United States" and defined technological literacy as "an understanding of the nature and history of technology, a basic hands-on capability related to technology, and the ability to think critically about technological developments". "One of the recommendations followed from the Committee's report was to strengthen the presence of technology in formal and informal education through integration of technology content into K-12 standards, curricula, and instructional materials.

The targets of this research are the ongoing efforts in public schools to educate students about technology. In particular, we are interested in the process of development of the Technology and Engineering Curriculum Framework and its inclusion in Massachusetts state standards and later using the data collected from this research to empirically test some of the claims of Nonuniversal Theory. ${ }^{11}$ Nonuniversal theory provides a powerful framework for analysis of the curriculum change based on the development of domains of knowledge and expertise on a Universal to Unique continuum which includes pancultural, cultural, disciplined, and idiosyncratic sequence of organized domains. Having engineering standards in the state frameworks makes this discipline a part of the cultural domain, that "expects every child in the cultural group to be able to achieve a certain level of mastery" rather than leaving this knowledge only for people interested in pursuing the field of engineering.

For our research purposes we designed a mixed method study. We developed research instruments to conduct a quantitative survey as well as qualitative exploration based on semistructured interviews. The interview participants represented the Department of Education, the university community, the state legislature, and educational advocacy groups. To better explore our research question we collected data from legal documents and from various research- based publications. 
In this study, we present the analysis of the qualitative data from the semi-structured interviews that focus on the process of interpretation of the technology and engineering education for the K12 system.

\section{Literature Review}

According to the Progress report from the Secretary of Education, Massachusetts Education Reform Act of 1993 called for major changes in public education over a seven year period. Proposed changes required a school council in every school, continuing education for educators, more authority for principal, better defined roles for school committees, and clear, concise and measurable statewide standards for students and schools ${ }^{2}$. Section 1D of the Educational Reform Act called for statewide curriculum frameworks and learning standards for all students in all core academic subjects:

"The board shall direct the commissioner to institute a process to develop academic standards for the core subjects of mathematics, science and technology, history and social science, English, foreign languages and the arts. The standards shall cover grades kindergarten through twelve and shall clearly set forth the skills, competencies and knowledge expected to be possessed by all students at the conclusion of individual grades or cluster of grades... "

The inclusion of technology and later technology/engineering track as a part of the science and technology/engineering standard highlights the importance of the incorporation of a new discipline in the core public schools curriculum. Historically, changes in core disciplines do not happen often. The establishment of the traditionally recognized core subjects can be traced back to 1893 , when the Reports of the Committee of Ten came out. ${ }^{3}$ The primary aim of these reports was to develop a common high school curriculum. These reports stated that high schools should offer language, science, history, and mathematics as major subjects. It is interesting to note, that the choice of these core disciplines did not change much since that time, although some efforts to include technology education in public schools had been made. For example, an article in the Science journal published in 1886 describes the effort to include "technical education and manual instruction in the public school system". 4 The board of education appointed a special committee to write a report on technical education that was later presented:

"The report emphatically favors the introduction of manual training into the public-school system, and points out that it may be accomplished in one of two ways: first, separate schools for manual training may be established: or, secondly, it may be made part of the regular course of study, as now pursued in the various schools."

This report had a "favorable reception" with the press and the education board but was not approved for immediate action, stating that "the proposed advance in the common-school system of the metropolis will soon become an accomplished act". 
The "soon become an accomplished act" was finally realized in Massachusetts which become the first state in the nation to require an engineering component be taught at all levels of the public schools.

"This is historic. With the vote, the state will introduce engineering to K-12 learning," said Tufts University School of Engineering Dean Ioannis Miaoulis, chairman of the technology-engineering advisory panel. "Massachusetts will be the first state in the country to do this. We will also be a world leader." The Boston Herald, 2000.

In the current study we address questions such as: What was the interpretation of technology education during the frameworks development? What was the process of including engineering discipline in the standards? What is the significance of having engineering in the standards?

\section{Methods}

To explore the factors that contributed the most to the inclusion of technology/engineering standards to the state frameworks, we designed the mixed methods research study. We developed research instruments to conduct a quantitative survey as well as qualitative exploration based on semi-structured interviews. To better explore our research question we also collected data from legal documents and various research-based publications.

\section{Participants}

Participants for the current study were five contributors to the development and inclusion of Technology and Engineering standards in Massachusetts's curriculum. ${ }^{5}$ They represented the university community and the State Department of Education. Written explanatory letters were provided prior to the interviews and the consent forms were secured for all participants.

\section{Measures}

We developed research instruments for the qualitative exploration. Semi-structured interviews were conducted to investigate the process of curriculum change in Massachusetts. During the interviews participants were asked about the extent of their involvment in policy change, and their experiences in the process of integration of Engineering and Technology in cthe urriculum frameworks.

\section{Data Collection}

Participants were contacted via e-mail with a request to schedule an interview. Interview times varied, ranging from 30 to 60 minutes. Variations were primarily a result of some participants giving brief answers, focused primarily on their direct involvement with the process, and some participants giving more detailed explanations providing a broader overview of the standards development and inclusion in the curriculum frameworks. Due to their work schedules, two out of five participants preferred to have an interview via phone. The other three participants agreed to meet at their work places. Interviews were audiotaped and subsequently transcribed. 


\section{Results}

We begin by reporting results on the interpretations of the technology content for K-12 education, followed by an analysis of the participants interview responses about the decision making process to include engineering in the standards and its significance on a national scale.

\section{Science and Technology Standards}

During the interviews, all the participants brought forward the problem that occurred during the Science and Technology framework development - how to interpret the meaning of technology education for the school curriculum. In other words, how should the teachers teach the Technology content and what should the Technology standards look like.

The Educational Reform Act of 1993 that required creating the core academic subjects, including Science and Technology, did not provide a guiding framework for technology education, what led to questions about how technology should be defined and taught.

Addressing this important issue, one of the interviewees said that multiple representations of Technology standards resulted in a debate:

"It was a debate about what was meant by technology. Did it mean things like computers and software applications or did it mean, what at the time was still industrial arts just changing over to technology education."

Some of the interviewees reflected on this debate, presenting both sides of the argument - the view of Technology education as a traditional "shop" class or the idea of infusing the science and mathematics concepts to make the content more academic. In particular, one of the interview participants noted that some people responsible for the frameworks development connected the Technology education to the Industrial Arts that had a stigma of a "trade" subject attached to it.

The alternative view of connecting science and technology was mostly stemmed from earlier works, such as Science for all Americans ${ }^{6}$ and National Science Benchmarks. ${ }^{7}$ The participant explained:

"The prevalent approach to science during the 1996 Science and Technology standards development was largely based on the Science for all Americans and National Science Benchmarks that were based on the Science, Technology, and Society framework. There is the straight science component, there are technologies that are used or produced based on it, and the relationship of both of these to the society. There was this interconnection of those three things that helped to develop a general framework. Technology was viewed as a tool for someone to use, to enhance the lifestyle of citizens and all those things".

Despite the difference in the interpretation of the meaning of Technology education, all five study participants agreed on the importance and urgency at the time of helping students to become more technically literate. One of the participants said: 
"As a whole society needs to know more about it and improve their technological literacy so that they can make better informed decisions on policies, on personal choices, on choices that affect the environment and to do so they need to be able to think critically of technologies".

\section{Science and Technology/Engineering Standards}

In the revised version of the Massachusetts Science and Technology curriculum framework in 2001, the title of the framework was changed from the Science and Technology to Science and Technology/Engineering. The Engineering discipline became part of the core curriculum standards. During the interviews we asked the participants to discuss the process of the inclusion of Engineering in the standards.

The general consensus from the interviews was that addition of engineering was an important step in making technology education more academic in nature, by integrating science and mathematics and at the same time preserving the knowledge of the building and design skills. One of the interview participants said:

"Originally Technology was defined vaguely and switching to technology/engineering made more sense."

"There is more recognition of technology and engineering".

One of the participants mentioned that some of the framework development team members did not see the inclusion of Engineering as a compliment to the curriculum. They thought engineering would be too difficult and would serve only very specific niche of students.

Another participant noted that because the engineering framework provided a nice range of learning experiences, it had potential to accommodate various educational needs.

"Engineering allowed us to include some of the more traditional physics principles as well as the fields or the job factors of technology. You have manufacturing, transportation, and construction right alongside or merged with engineering design, energy, power those kinds of things. All of these merged into one category called Technology/Engineering".

\section{The significance of including Engineering in the standards}

During the interviews, we asked the participants about the significance of having engineering in the state standards. All of them responded that the most distinguishing fact is that Massachusetts was the first state in the nation to include Engineering in the curriculum framework. One of the participants said:

"Having engineering standards was the first time that anybody in the country articulated it as a K-12 discipline".

"We were the first state to create a discipline called Technology/Engineering. And it was a compromise". 
While many of the states have technology education standards, which are largely based on the engineering design process, they still don't have engineering explicitly stated. One of the responses presents this point:

"The other states do not have word engineering specifically in their frameworks. Using the word engineering was a big deal. I think part of it is that in the general public people just don't understand what engineering is. They have heard of technology and think of computers that is something we should change".

Interview participants also discussed the importance of having engineering in the standards as a way to have accountability. One of the participants noted:

"The main thing that standards added was accountability. It added a lot of weight. What's taught is what's tested and what's tested is what's in the standards".

\section{Discussion}

According to the report on Technological Literacy ${ }^{1}$, most people think of technology in terms of its artifacts, such as computers, microwave ovens, cell phones, and many other devices we are so used to these days. The definition of technological literacy, as proposed by the report, incorporated three dimensions - knowledge, ways of thinking and acting, and capabilities.

Through the interviews in our study we explored the process of interpretation of technology education to make it relevant to the school curriculum. Based on the received responses, it was clear that the meaning of technology education went through several iterations before it was implemented in the curriculum. The traditional view of technology education, based on the development of building skills, had to be infused with science and mathematics concepts, in order to be effective in teaching students about the current technological developments.

The new recognition of the need to make technology education more academic in nature required a change in vision. Engineering discipline was added to the Science and Technology standards in Massachusetts and became a part of the core curriculum. In the interviews participants discussed the inclusion of engineering as a necessary step to make technology education more recognized and help to provide a wider range of learning experiences through connection of physics and mathematics concepts to the real life applications.

Although many states had technology standards and as part of these standards taught about the design process, Massachusetts was the first state in the nation to include engineering in the state curriculum frameworks. As one of the participants noted, it was the first time that anybody in the country was able to articulate engineering discipline for the K-12 levels. Participants also pointed out that having engineering in the standards raised the level of accountability for what is being taught in the classroom. 


\section{Conclusion}

It is hard to overestimate the importance of this educational policy change as a historical event as well as a powerful model for other states to learn from. From the literature, we have learned that the core curriculum disciplines do not change often. Engineering frameworks inclusion in the state standards was a significant event that resulted from collaborative work by the Department of Education, university community, state legislature, and the educational advocacy groups, that brought the vision to reality.

In this study, we explored important questions discussed during the standards development and decision-making process about the meaning of the technology education for the K-12 system and the need for the inclusion of engineering discipline in the state curriculum framework.

The results of our work could be a useful source of information to help others make an impact on the system of education in a meaningful way.

\section{Bibliography}

1. National Academy of Engineering. (2002). Technically Speaking. Washington, D.C.: National Academy Press.

2. Massachusetts Education Reform Act of 1993 http://www.doe.mass.edu/edreform/

3. The Report of the Committee of Ten (1894). The School Review, Vol. 2., No.4, pp.193199.

4. Technical Education(1886). Science, Vol. 8, No. 195, pp. 381-382.

5. Science and Technology/Engineering Curriculum Framework (1996) http://www.doe.mass.edu/frameworks/scitech/1996/

6. Science and Technology/Engineering Curriculum Framework (2001) http://www.doe.mass.edu/frameworks/scitech/2001/

7. Science and Technology/Engineering Curriculum Framework (2006) http://www.doe.mass.edu/frameworks/scitech/1006.pdf

8. Science for all Americans (1991).

9. National Science Educational Standards (1996). Washington, D.C.: National Academy Press.

10. Ames, N. at el. (2001). School Reform. Jossey-Bass, Inc.

11. Feldman, D. (1994). Beyond Universals in Cognitive Development. $2^{\text {nd }}$ ed. Greenwood Publishing Group, Inc. 
12. Bellack, A. (1969). History of Curriculum Thought and Practice. Review of Educational Research, Vol. 39, No. 3, Curriculum, pp. 283-292.

13. Background Paper: Eliminating the General Track http://www.doe.mass.edu/edreform/

14. Education Fact Sheets

http://www.doe.mass.edu/edreform/

15. Education Reform Progress Report http://www.doe.mass.edu/edreform/edreformreport/erprogrpt597-1.html

16. First Annual Implementation Report http://www.doe.mass.edu/edreform/1st_Imp/TOC.html 